Летом около половины всех волн холода (см. табл. 1) сопровождается осадками, но в отдельные месяцы повторяемость «дождливых» волн холода существенно различается при перепадах средней суточной температуры различной интенсивности. Так, наиболее часто интенсивные волны холода сопровождаются осадками в июне $(71 \%)$ и около половины в июле и августе (см. табл.1). Волны холода средней интенсивности сопровождаются осадками во все летние месяцы примерно в половине случаев. Слабые же волны наиболее часто сопровождаются осадками в июле (73\%), несколько меньше в июне $(67 \%)$ и совсем редки осадки на фоне волны холода в августе (всего 26\%).

Летом (см. табл. 2) осадками сопровождается очень малое количество теплых волн, только 20\% от их общего числа. Однако по месяцам повторяемость дождливых волн различной интенсивности неодинакова. Так, в июне при слабых волнах тепла осадков практически не выпадает (5\%). Из средних и интенсивных волн осадками сопровождается примерно четверть. Дождливые волны тепла в июле составляют примерно треть от всех волн в этом месяце. В августе меньше всего осадков выпадает на фоне волн тепла средней интенсивности (10\%). Из слабых и интенсивных волн тепла дождливые составляют четверть.

Осадки, выпадающие при перепадах среднесуточной температуры, очевидно, имеют фронтальный характер. Однако за исследуемый период осадки указанных величин выпадали и на фоне слабых колебаний среднесуточной температуры воздуха $\left(<3^{\circ} \mathrm{C}\right)$. Таких случаев отмечено за летний период в июне 10 , в июле -9 и в августе -8 . Эти осадки, по-видимому, относятся к внутримассовым.

Полученные закономерности выпадения осадков при различных перепадах среднесуточной температуры воздуха предполагается использовать для дополнения прогноза резких колебаний среднесуточной температуры воздуха для месяцев летнего периода.

\section{Библиографический список}

1. Морозова С.В., Полянская Е.А., Пужляккова Г.А., Фетисова Л.М. К вопросу обобщения гидрометеорологической информации // Изв. Сарат. ун-та. 2004. Т. 4, вып. 1-2. C. $157-161$.

2. Морозова С.В., Полянская Е.А., Пужлякова Г.А., Фетисова Л.М. Региональная модель долгосрочного прогноза резких изменений температуры воздуха с месячной заблаговременностью (статья) // Изв. Сарат. ун-та. 2004. Т. 4, вып. 1-2. С. 195-198.

3. Морозова С.В., Полянская Е.А. К вопросу регионального моделирования хода элементов погоды в течение месяца // Актуальные проблемы земледелия. Саратов, 2005. C. $173-177$.

4. Полянская E.A. Синоптические процессы и явления погоды Нижнего Поволжья. Саратов, 1986. 208 с.

\title{
ИСТОРИЯ ИЗУЧЕНИЯ ПОЙМЕННЫХ ЛАНДШАФТОВ ВОЛГИ В РАЙОНЕ САРАТОВА
}

\section{М.Ю. Проказов}

Саратовский государственный университет, кафедра физической геологии и ландшафтной экологии E-mail: mp37@mail.ru

Статья посвящена истории изучения пойменных ландшафтов Волги в районе Саратова. В работе используются материалы исследований поймы Волги, собранные разными учеными в течение XX века. Выделены исторические периоды исследования Волги в районе Саратова. Основное внимание в статье уделено прикладным исследованиям, направленным на выявление ландшафтных характеристик волжской поймы, структуры и динамики пойменных геосистем.

History of Studying of Water-Meadow Landscapes of the Volga River in Saratov Area

\section{M.Yu. Prokazov}

Article is devoted to a history of studying of water-meadow landscapes of the Volga river in Saratov area. Various stages in research of the river are viewed here. There is made an attempt of selection of the information, touching a problem from the landscape-ecological point of view. The main attention in the article is given to applied researches,

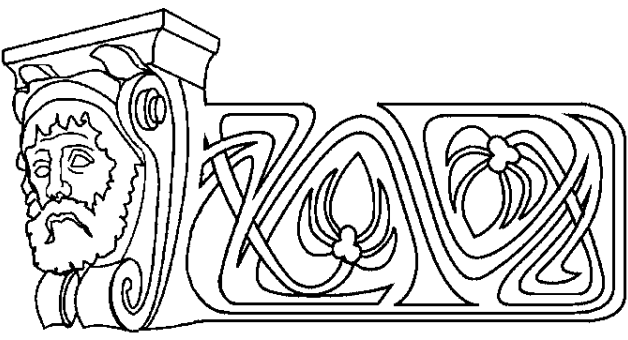

the character of their realization, purposes of scientists who were engaged in studying of the Volga during different years. In the end of this work conclusions on necessity of modern researches are drawn, their purposes and orientation are defined.

Уникальная природа волжской поймы в районе Саратова привлекала внимание ученых на протяжении многих лет. ХХ в. стал определяющим в судьбе реки. Именно в этот период Волга стала объектом многоплановых научных исследований. В то же время облик реки значительно изменился вследствие масштабных антропогенных преобразований. Волга, которую изучали ботаники, зоологи, ландшафтоведы, климатологи на протяжении первой половины прошлого столетия, стала совершенно «другой рекой» для ученыхисследователей после 1958 г., когда было завершено строительство Волгоградской ГЭС. Созда- 
ние Волгоградского водохранилища определило необходимость обновления значительной части картографического, зооботанического, микроклиматического материалов.

Цель данной статьи - определить различные этапы изучения поймы Волги, оценить изменение характера исследований реки, их методов и направленности в течение XX века. Анализ опубликованных материалов разных лет, их систематизация и генерализация - основные задачи, которые решались в ходе работы над статьей.

В 1900 г. благодаря содействию Саратовского общества естествоиспытателей и любителей естествознания была организована Волжская биологическая станция, перед которой поставили задачу изучить природу Волги в обозначенном районе, уделив основное внимание биологии и видовому составу рыб и микроорганизмов реки [1]. В течение последующих лет цели и задачи ученых, работавших на биологической станции, во многом расширились и определили комплексность проводимых исследований.

Биологические станции впервые возникли во второй половине XIX в. на озерах зарубежной Европы и содействовали формированию новой науки - лимнологии. Первая речная биологическая станция появилась в 1894 г. в штате Иллинойс (США) на одноименной реке [1]. Волжская биологическая станция в Саратове стала первой в своем роде на территории Европы [1]. С её появлением изучение Волги поднялось на новый, значительно более высокий научный уровень. Несмотря на то что исследования, проводимые станцией, носили в основном биологический характер, недостаток информации о Волге в других научных дисциплинах заставил ученых применить комплексный подход к изучению реки. Этот существенный момент сделал итоги почти 25-летней деятельности станции ценным источником общегеографической информации и ландшафтных характеристик волжской долины в районе Саратова.

В течение многих лет публиковались отчеты о деятельности Волжской биологической станции, анализируя которые можно проследить ход работ и развитие научных идей ее сотрудников. В разные годы на станции работали биологи В.П. Зыков, В.И. Мейснер, П.Н. Быстрицкий, А.С. Скориков, Е.Н. Болохонцева и др.

По итогам первого года работы станции был составлен отчет, в котором, помимо описания различного биологического материала, собранного станцией, приводится и ряд экологических, хозяйственных, экономических и некоторых других проблем Волги того периода: хищническое истребление мальков (в особенности стерляди), устройство рыбных кладбищ, загрязнение реки нефтью, отсутствие правильного надзора за рыбопромышленниками, рыбные паразиты [1]. В отчете за 1902 г. дан краткий физико-географический очерк p. Волги у Саратова. Его составил В.И. Мейснер по таким материалам, как статья «Волга»
Л.Е. Белявского в энциклопедическом словаре Брокгауза и Эфрона, статья Германа «Физические очерки Саратовской губернии» (Труды Саратовского общества естествоиспытателей и любителей естествознания, т. 2, вып. 4), «Россия - полное географическое описание нашего отечества» [2]. В очерке дается гидрологическая характеристика реки, описывается геологическое строение территории, по которой течет Волга, приводятся метеорологические показатели. Структуру и характер изложенного в очерке материала может наглядно продемонстрировать нижеследующая выдержка: «...главной отличительной чертой Волги от рек Западной Европы является именно эта медленность течения (около 6-ти верст в час), обусловливаемая равнинностью страны и небольшой сравнительной высотой истока... Почти на всем протяжении своем Волга протекает по легкоразмываемым породам пермской (песчаники, рухляки, известняки), меловой (мел, песчаник, глины), и третичной (пески, песчаники, кремнистые глины) систем» [2, с.12]. Интересна интерпретация влияния силы Кориолиса на формирование волжских берегов: «Размывание правого берега совершается, согласно закону Бэра, энергичнее, причем отмытые части уносятся в громадном большинстве случаев к левому берегу или по течению вниз, а сама река мало-помалу перемещается к размываемому правому берегу. В некоторых случаях это явление в своей второй стадии получает другой характер, что наблюдается как раз в рассматриваемой области - у Саратова - а именно: река, размывая правый берег, отлагает отмытые частицы тут же возле него, а потому, в конце концов, получается, что главное течение отошло к левому берегу, а у правого осталось лишь побочное - воложка» [2, c.12,13]. Далее следует описание метеорологической обстановки рассматриваемой местности. В частности, говорится, что «... свободной ото льда Волга под Саратовом бывает 235 дней в году» [2, c.13], и приводится весьма интересное описание режима реки: «...прибыль воды бывает настолько значительна, что поднимает уровень реки на 18-20 аршин (12-14 м) против межени. Все мели, песчаные острова и значительная часть левого лугового берега в это время затоплены, быстрота течения увеличивается почти вдвое против меженного, и Волга представляется почти необозримой равниной воды, быстро несущей с собой массы минеральных взвешенных остатков и органического детрита. Все старицы, ильмени (береговые озера) - все сливается под одно с Волгой. Лишь два острова никогда совершенно не затапливаются рекой: Зеленый, или Беклемишев, находящийся немного выше Саратова, и Ильинский, или Казачий, лежащий против нижнего конца города. Такова Волга в половодье... Уже в июле (вторая половина) Волга течет в своих берегах - стала на межень, как говорят волжские жители. В эту пору саратовская Волга представляет довольно безотрадную картину: громадная площадь желтых 
песчаных наносов представляется глазам зрителя, сама же река как-то теряется среди этой песчаной пустыни...» $[2$, с.13,14]. Как видно из приведенной цитаты, современная Волга лишь весьма отдаленно напоминает незарегулированную, ведущую себя согласно законам природы, а не прихотям человека, великую русскую реку. Далее в рассматриваемом очерке В.И. Мейснера говориться о проблемах судоходства на Волге в засушливые летние месяцы, о составе дна реки: «... в громадном большинстве случаев оно песчаное и лишь в заливах и старицах поверх песка отлагается более или менее толстый слой ила. У городского берега дно загрязнено всевозможными органическими остатками» [2, с.15]. «Краткий физический очерк р. Волги у Саратова» В.И. Мейснера предоставляет важную информацию о жизни реки того времени и позволяет сравнивать Волгу прошлых лет с нынешними Волгоградским и Саратовским водохранилищами.

В течение следующих лет работы биологической станции делаются попытки привлечь к исследованиям специалистов других областей знания. Интересна цитата из отчета по итогам 1903 года: «...станция отнюдь не безразлично относится к исследованиям другого характера, она также считает своей обязанностью, по мере сил, быть полезной и в этом направлении. Кроме того, свободные у себя места она охотно предоставляет для работы лицам, желающим познакомиться с природой, понаблюдать жизнь в воде, как отдых от обычных занятий...» [3, с. 9].

В 1905 г. станция начинает проводить исследования пойменных озер Волги. Так, В.И. Мейснер пишет в отчете 1908 г. о пойменных волжских озерах: «Если мы бросим взгляд на план р. Волги, приуроченный к меженному времени, то увидим, что все острова и весь пойменный берег, заливаемые в весеннее время водами реки, усеяны многочисленными озерами всевозможной величины и формы. Во время весеннего водополья все эти озера заливаются волжской водой и прекращают свое самостоятельное существование, сливаясь под одно с Волгой и отдавая ей большую часть своей фауны. Со спадом воды эти озера снова начинают свою самостоятельную жизнь, продолжающуюся до следующей весны, а для некоторых - вследствие высыхания - и того меньше. За этот период их самостоятельной жизни, жизни совершенно отличной от самой реки, в них развивается в громадном большинстве случаев богатейшая фауна» [4, с.1-3]. Далее описываются трудности, с которыми ученые столкнулись при изучении островных озер: «... приходилось прибегать к способу, с прелестями которого мы познакомились еще в 1903 г. и о котором в своем отчете упоминает А.С. Скориков - это перетаскивание лодки без всяких приспособлений, волоком или на плечах, иногда на довольно значительные расстояния» [4, с.2]. Характеристика исследованных озер наглядна, точна и, можно сказать, детальна.
При их описании приводятся данные о характере дна, в основном песчаного, покрытого слоем ила, температурного режима (фиксировалась температура верхнего слоя воды, равная 29,4 $\mathrm{C}$ ), рассматривается жизнь озер в паводок и межень, большое внимание уделяется их флоре и фауне. В 1905 г. изучается Усть-Курдюмский затон, предпринимаются 35 маршрутов в различные участки Волги в районе Саратова на принадлежавшем станции катере «Натуралист». В отчете за 1905 г. также говорится об актуальности экспедиционного способа исследований [5].

Необходимо отметить личные наблюдения сотрудников станции, дневники экспедиций. Несмотря на то что в большинстве своем эти материалы носят описательный характер, благодаря им можно представить особенности природы и ландшафтов Волги тех лет. Так, все тот же В.И. Мейснер описывает «блуждание» коренного течения Волги у Саратова, которое благодаря особенностям характера протекавших в 1900 г. русловых процессов, переформированию песчаных наносов и проток напротив города стало протекать у противоположного Саратову левого берега [2].

Деятельность станции в 1905-1913 гг. интересна тем, что в этот период делаются попытки проведения первых топографо-геодезических работ на исследуемой территории. В 1907 г. проводится мензульная съемка пойменных озер, уделяется много внимания разработке планов реки. В основу карты-плана Волги в районе деятельности станции (от Увека до Усть-Курдюма), представленной в отчете за 1908 г., был положен план реки ведомства путей сообщения съемки инженера А.Е. Маркова 1903 года. В отчете говорится, что «этот план в районе островов Рябишина, Котлубани и Тотинского был дополнен маршрутно-глазомерной съемкой, произведенной в 1905 и в 1908 годах» [4, с.3].Таким образом, ученые пытались восполнить пробелы в предыдущих исследованиях и придать своей работе более разноплановый характер. В то же время проводятся исследования волжских затонов, более подробно описывается характер течения реки, ее донных отложений, режима. К тексту отчетов прилагаются планы пойменных озер и исследуемых участков Волги, фотографические изображения.

Станция проработала до середины 20-х гг. прошлого века и оставила после себя богатейший научный материал, обеспечив базу для дальнейших исследований Волги. За время своей работы сотрудникам станции удалось собрать коллекцию представителей фауны реки, подробно описать видовой состав рыб и микроорганизмов Волги в районе Саратова и в целом дать представление о природе реки начала прошлого века.

В советский период исследования ученых были направлены на изучение хозяйственного потенциала реки. Обсуждалась и притворялась в жизнь идея формирования проекта «Большая 
Волга» [6]. Научные или, точнее будет сказать, хозяйственные планы, разработанные в 30-е гг., начинают осуществляться в послевоенное время. Для обеспечения региона электроэнергией строятся Волгоградская и Саратовская ГЭС; потребность сельского хозяйства в увеличении площадей орошаемых земель обеспечивают созданные водохранилища, от которых отводится сеть каналов в наиболее засушливые территории. Строительство каскада волжских водохранилищ коренным образом преобразовало самую большую реку Европы. Ученые давали множество оптимистических прогнозов о дальнейшей судьбе реки, о восстановлении ее природных функций [7], но, к сожалению, они не сбылись. Проблемы, характерные для водохранилищ, не обошли стороной и образованное в 1958 г. «Сталинградское море». По истечении нескольких лет появилась необходимость оценить те изменения в природе, которые явились следствием зарегулирования стока Волги, и уточнить научные данные, лежащие в основе прогнозирования ближайших и отдаленных последствий сооружения водохранилищ [8]. Осуществлению этой задачи были посвящены комплексные экспедиции Саратовского университета по изучению Волгоградского и Саратовского водохранилищ.

Проводимые в 70-х гг. XX в. комплексные экспедиции были направлены на решение целого ряда проблем и вопросов, возникших после формирования Волгоградского водохранилища. Участие в них принимали ученые различных специальностей: метеорологи, геоморфологи, почвоведы, гидробиологи, ботаники и зоологи [8]. Для автора данной статьи наибольшую ценность представляет именно прикладная направленность исследований в тот период. В этом плане наиболее интересны работы климатологов СГУ С.А. Волкова, Е.В. Ишерской и Э.Ф. Скоробогатовой по характеристике климатических показателей в районе водохранилища [8, 9], а также работы геоморфологов СГУ Г.И. Леонтьева и Л.В. Деева по изучению морфологии преобразованной поймы [8-12]. В своих статьях, посвященных микроклиматическим характеристикам озеровидных расширений, режиму подтопленных островов водохранилища, и других работах С.А. Волков приводит целый ряд экспедиционных данных, полученных в ходе личных исследований. Помимо графиков суточного хода температур воды и воздуха, распределения влажности воздуха у поверхности водохранилища Волковым приводится описание маршрутов с их планами, даются общие характеристики изучаемой местности [8]. Интересны статьи Г.И. Леонтьева и Л.В. Деева, посвященные морфологическим процессам на территории Волгоградского водохранилища [11]. Авторы анализируют ход русловых и эоловых процессов, гидролого-морфологические показатели Саратовско-Марксовского расширения водохранилища, сопровождая текст различными схемами, таблицами, фотоматериалами и рисунками, иллю- стрирующими ход описываемых преобразований поймы. Можно привести некоторые выводы из их статей: «...несмотря на преобладающий размыв внешней части левобережных островов, их пойменная часть нарастает как в плане, так и в высоте. Значительное количество наносов от размыва островов отлагается в пойменном мелководье. Вследствие зарастания островов количество песка, поступающего вглубь поймы эоловым путем, в настоящее время уменьшилось... На один метр длины берега данного района ежегодно в водохранилище поступало около $20 \mathrm{~m}^{3}$, а выносилось около $10 \mathrm{~m}^{3}$ эолового материала. Приведенные величины, несмотря на их приближенность, показывают, что эоловые процессы могут играть существенную роль в различных сторонах жизни водохранилища, и в частности в отрицательной составляющей его баланса заиления, до сих пор не учитываемой при исследовании. Поэтому при комплексных исследованиях на водохранилищах и больших реках эоловым процессам должно быть уделено большее внимание, чем это было сделано за последние годы» [11, с.34].

Анализируя содержание трудов комплексной экспедиции, публиковавшихся в течение нескольких лет и отражавших итоги различных исследований, прослеживается их общегеографическая направленность.

Экспедиционный метод позволил ученым наглядно описать различные характеристики Волги, отразить реальную ситуацию на реке, выделить возникшие проблемы и тенденции развития пойменных ландшафтов. Стало очевидно, что пойма претерпела значительное преобразование. Поверх затопленной огромной территории стали формироваться природно-антропогенные ландшафты, скорость течения реки уменьшилась более чем в два раза, изменились ход русловых процессов, видовой состав флоры и фауны, микроклиматические показатели. Суммируя результаты наблюдений ученых можно представить структуру ландшафтов преобразованной волжской поймы, которые на тот момент продолжали свое формирование. По прошествии двух десятилетий после строительства Волгоградской ГЭС прогноз ученых о формировании уровня равновесия и прекращения абразии не оправдался. Более того, обострились экологические и социальные проблемы на территориях, прилегающих к водохранилищу, экономическая же выгода от его образования и в настоящий момент ставится под сомнение. Тем не менее в трудах комплексных экспедиций практически нет работ, непосредственно описывающих пойменный ландшафт, работ, которые могли бы показать общую картину преобразованных, а некоторые ученые считают и «уничтоженных» пойм.

Комплексные экспедиции по изучению Волгоградского и Саратовского водохранилищ, безусловно, сыграли важную и заметную роль в исследовании Волги, но прошло уже более четверти века с момента их завершения, что, учитывая 
сложность и динамичность аквальных геосистем, определяет необходимость обновления полученных в ходе экспедиционных работ данных [13].

В 80 -е гг. ХХ в. исследования Волги не прекращались, но носили уже менее масштабный характер. С началом 90-х гг. социальноэкономическая ситуация в стране не способствовала развитию науки, что в значительной степени затрудняло организацию и проведение каких-либо исследований реки. Таким образом, назрела необходимость новых исследований поймы Волги [13]. В настоящее время вряд ли стоит надеяться на организацию экспедиций, подобных проходившим в 70-е гг., но все же проблемы современного состояния волжской поймы в районе северной части Волгоградского водохранилища не могут оставаться в стороне от научных исследований. Озеровидное расширение Волгоградского водохранилища в акватории от г. Саратова до г. Маркса, так называемая «Красноярская пойма», с множеством островов, проток, затонов, озер и песчаных кос во многом сохранило черты «старой Волги». Эти безусловно уникальные ландшафты являются интереснейшими объектами для исследователягеографа. Опираясь на картографический материал разных лет и возможности современных ГИС-технологий, используя ландшафтный подход и опыт предыдущих исследователей, можно добиться значительных результатов в изучении пойменных геосистем Волги в районе Саратова.

Подводя общий итог, отметим, что исследования Волги в районе Саратова носили различный характер в зависимости от задач, ставившихся перед учеными. Можно выделить 4 этапа исследований:

- первый, длившийся с начала XX в. и до 1917 г., - был посвящен в основном изучению биологического разнообразия реки. Были сформулированы первые научные описания поймы, проводились базовые топографические работы на акватории Волги в районе Саратова;

- второй относится к довоенному времени (30-е гг.) и первым десятилетиям после Великой Отечественной войны и характеризуется в основном исследованием хозяйственного потенциала реки, масштабным преобразованием ее природы;

- третий период - 70-е - начало 80-х гг. время комплексных экспедиций, направленных на оценку антропогенных преобразований, вызванных зарегулированием Волги;

- четвертый - конец 80-х - 90-е гг. - активность исследовательской работы по изучению поймы резко снижается, сами исследования носят разрозненный характер.

Очевидно, что следующий период изучения поймы Волги должен носить природоохранный характер, а научную деятельность следует направить на выявление наиболее сохранившихся пойменных ландшафтов, определение оказываемой на них антропогенной нагрузки и формулировка основных мер по их защите.
В 2008 г. с момента образования Волгоградского водохранилища пройдет уже 50 лет. Некоторые исследователи считают, что этого времени вполне достаточно для завершения формирования его облика, другие, напротив, утверждают, что такой период времени незначителен и процессы, вызванные зарегулированием реки, еще не завершились. В любом случае, чтобы подтвердить или опровергнуть ту или иную гипотезу, дать характеристику современного состояния пойменных ландшафтов, определить тенденции в их развитии и меры, необходимые для их охраны, следует продолжить исследования Волги.

\section{Библиографический список}

1. Отчет о деятельности Волжской биологической станции за летние месяцы 1900 г. // Тр. Волжской биологической станции. Саратов, 1900. T.I, вып.1. С. 1-5.

2. Отчет о деятельности Волжской биологической станции за лето 1901 г. // Тр. Волжской биологической станции. Саратов, 1902. Приложение к Т.ІІ. С. 12-15.

3. Отчет о деятельности Волжской биологической станции за лето 1902 г. // Тр. Волжской биологической станции. Саратов, 1903. Т.ІІ, вып.1. С. 9.

4. Мейснер В.И. Гидробиологические очерки некоторых поемных озер долины реки Волги у Саратова // Tр. Волжской биологической станции. Саратов, 1909. T.IV, вып.5. C. 1-3.

5. Отчет о деятельности Волжской биологической станции за 1905 г. // Тр. Волжской биологической станции. Саратов, 1906. Т.ІІІ, вып.1, С. 3.

6. Проблемы Волго-Каспия // Тр. ноябрьской сессии 1933 г. Л., 1934. С. 638.

7. Гориев В.И. Преобразование волги // Сельское хозяйство Поволжья. 1960. №5 (ж). С. 24-27.

8. Тр. комплексной экспедиции Саратовского университета по изучению Волгоградского и Саратовского водохранилищ / Под ред. А.С.Константинова. Саратов, 1970. Вып. $1.131 \mathrm{c}$.

9. Тр. комплексной экспедиции Саратовского университета по изучению Волгоградского и Саратовского водохранилищ / Под ред. А.С.Константинова. Саратов, 1973. Вып. 3.147 c.

10. Тр. комплексной экспедиции Саратовского университета по изучению Волгоградского и Саратовского водохранилищ / Под ред. А.С.Константинова. Саратов, 1975. Вып. 4.144 c.

11. Тр. комплексной экспедиции Саратовского университета по изучению Волгоградского и Саратовского водохранилищ / Под ред. А.С.Константинова. Саратов, 1976. Вып. $6.96 \mathrm{c.}$

12. Тр. комплексной экспедиции Саратовского университета по изучению Волгоградского и Саратовского водохранилищ / Под ред. А.С.Константинова. Саратов, 1979. Вып. 8.104 c.

13. Проказов М.Ю. Изучение пойменных геосистем Волгоградского водохранилища // Развитие физической географии и ландшафтной экологии в Саратовском университете: Сб. науч. тр. Саратов, 2005.171 с. 